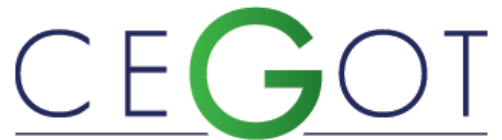

Centro de Estudos de Geografia e Ordenamento do Território
Geografia e Ordenamento do Território, Revista Eletrónica Centro de Estudos de Geografia e Ordenamento do Território http://cegot.org

CASTRO, MARIA

Universidade Federal de Minas Gerais, Escola de Arquitetura,

Departamento de Tecnologia - TAU

Rua Gonçalves Veloso 223,/301. 30380620 Belo Horizonte Brasil

Luizadecastro2000@gmail.com

CAstro, MARIA

DEA Ecole d'Architecture de Paris Belleville

Rue Nicolas Faltot, no 8. 93.100 Montreuil França

beatriz.castro@online.fr

\title{
Articulando a cidade global e a cidade justa: o Grand Paris Express e a "Terceira grande revolução urbana" de Paris
}

Articulating the global city and the just city: the Grand Paris Express and the "Third great urban revolution" in Paris

Referência: Castro, Maria; Castro, Maria (2018). Articulando a cidade global e a cidade justa: o Grand Paris Express e a

"Terceira grande revolução urbana" de Paris. Revista de Geografia e Ordenamento do Território (GOT), n. ${ }^{0} 15$ (dezembro)

Centro de Estudos de Geografia e Ordenamento do Território, p. 69-95, dx.doi.org/10.17127/got/2018.15.004

\section{RESUMO}

Encontra-se em curso, em Paris, a construção do Grand Paris Express (GPE), uma rede subterrânea de metrôs automáticos com mais de $200 \mathrm{~km}$ de extensão, incluindo 68 novas estações. O GPE deverá contornar a capital pela periferia, complementando o sistema de eixos centrípetos existentes que, até o momento, se organizam de forma radial. O objetivo é a construção de uma cidade sustentável, seja do ponto de vista econômico - por meio do posicionamento de Paris como centro econômico global - seja do ponto de vista social - por meio de propostas para a melhoria do quadro de vida dos habitantes e para a correção das desigualdades territoriais. O presente artigo apresenta o projeto e procura situá-lo nas discussões que suscita, em torno de temas tais como sustentabilidade, governança, gestão de impactos, entre outros, que se articulam entre dois polos: eficiência e equidade.

Palavras-chave: mobilidade urbana; Grand Paris Express; Cidade Global, Cidade Justa, sustentabilidade urbana.

\section{ABSTRACT}

In Paris, the construction of the Grand Paris Express (GPE) is in progress. The GPE is an underground subway network with an extension of over $200 \mathrm{~km}$ that includes 68 new stations. The GPE will circle the capital by its periphery, complementing the system of existing centripetal axes that have been organized radially so far. The objective is to build a sustainable city, both from an economic point of view - by positioning Paris as a global economic center - and from a social point of view - by improving the living conditions of the inhabitants and correcting territorial inequalities. This paper presents the project and seeks to situate it within the discussions that it raises, including themes such as sustainability, governance, impact management, among others, that are articulated between two poles: efficiency and equity. 
Keywords: urban mobility; Grand Paris Express; Global City, Just City, urban sustainability.

\section{Introdução}

Após muitas décadas de negociações, a "obra do século" está atualmente em plena efervescência na capital francesa. Trata-se da maior obra europeia de infraestrutura dos próximos dez anos, o dobro do CrossRail de Londres (JACQUE,2017) ${ }^{1}$ : a previsão inicial, em 2008, era de um gasto de cerca de 20,5 bilhões de euros (AUZANNET, 2012) em dez anos para as novas linhas e estações de metrô que formarão a Rede Expressa da Grande Paris (Grand Paris Express, ou GPE).

Com os reajustes, os projetos habitacionais do entorno e o planejamento urbano, as despesas podem elevar-se a mais de 108 bilhões de euros (JACQUE, 2017). O GPE está ligado à criação da nova metrópole da Grande Paris e indissociavelmente articulado com o desenvolvimento regional. O objetivo é a construção de uma cidade sustentável, seja do ponto de vista econômico - por meio do posicionamento de Paris como centro econômico global - seja do ponto de vista social - por meio de propostas para a melhoria do quadro de vida dos habitantes e para a correção das desigualdades territoriais.

A proposta é estruturada a partir da busca de densidade, da intensidade e da composição mista da cidade (AIGP, 2012). O primeiro elemento deste tripé é a ideia de cidade compacta, adaptada para a realidade da metrópole, numa organização que pode ser identificada como um "modelo de concentração descentralizada ou modelo policêntrico em rede": o objetivo deste modelo é a configuração de uma cidade que reúna diversos centros autônomos, conectados por transportes públicos eficientes (MADUREIRA, 2005, s.p.). O segundo elemento, articulado com o primeiro, é a intensidade da metrópole, que permite a rentabilização dos recursos da infraestrutura urbana a partir da intensificação do uso da terra e de redes de mobilidade, equipamentos sociais, redes de saneamento, energia e outras. Por fim, o terceiro elemento é a promoção de espaços multifuncionais, com uma

\footnotetext{
${ }^{1}$ Trata-se de uma obra de $100 \mathrm{~km}$ que corta a cidade na direção leste oeste e conta com $42 \mathrm{Km}$ de novos túneis, 10 novas estações e $50 \mathrm{~km}$ de novos trilhos - em operação, recebeu o nome de Elizabeth line (www.crossrail.co.uk).
} 
composição mista, incluindo habitação e outras atividades, assim como um mix de perfis populacionais.

O presente artigo procura situar a questão no quadro de uma dinâmica urbana que se constrói dentro dos "limites de elasticidade das técnicas e das vontades políticas" (ACSELRAD, 1999, p. 88). Inicialmente são apresentados os temas que norteiam a discussão: por um lado, a investigação da proposta de cidades compactas e do chamado modelo policêntrico em rede nas metrópoles, em suas implicações para a mobilidade urbana; por outro, duas orientações que polarizam a construção social da base técnico-material da cidade: a eficiência e a equidade. A proposta do GPE é, em seguida, exposta, dentro de uma perspetiva que contempla estas questões. Por fim, apresenta-se o estádio de evolução atual do empreendimento, que enfrenta dificuldades técnicas e orçamentárias.

\section{Mobilidade: cidades compactas e modelo policêntrico em rede}

Atualmente, parece existir um consenso entre instituições e governos, que reconhecem nas cidades compactas uma forma de melhorar a sustentabilidade, no que diz respeito ao sistema de transporte urbano (GAIGNÉ et al., 2012). Richard Rogers e Gumuchdjian (1997) estão entre os que defendem esta configuração e descrevem suas vantagens - dando destaque à questão do transporte. O planejamento eficiente do transporte e da mobilidade é imprescindível para o sucesso de qualquer cidade, mas, nas cidades compactas, é uma necessidade central. Aproximar os serviços e estimular a vida pública também significa reservar menos áreas para garagens e estacionamentos, espaços considerados monofuncionais e individualistas, numa perspetiva social, desestimulando a circulação de automóveis. Assim, a eficiência do transporte é garantida pelo maior número de deslocamentos em um menor espaço de tempo, o que só pode ser alcançado pelo traslado em massa: trens, metrôs ou qualquer outro transporte público de maior porte. A eficácia, porém, depende do atendimento a demandas particulares, que nem sempre conseguem ser supridas pelo transporte público. Assim, é necessário que haja a integração adequada entre os diferentes modais para que atendam desde as maiores até as menores escalas (ROGERS, GUMUCHDJIAN, 1997). 
A proposta de transporte das Cidades Compactas é considerar "pontos focais em volta dos quais as vizinhanças se desenvolvem" (ROGERS, GUMUCHDIIAN, 1997, p. 38). Estes pontos articulam os transportes em massa, que conectam as cidades umas às outras. Sendo multimodais, eles articulam também meios de menor porte, como o ônibus, ou as bicicletas, até os percursos que podem ser feitos a pé, atendendo a uma hierarquia de distâncias (ROGERS, GUMUCHDJIAN, 1997, p. 47).

Outra vantagem deste tipo de configuração urbana é a redução das distâncias percorridas diariamente, o que traz não somente um ganho de tempo, mas, principalmente, vantagens em termos ambientais - mais significativas do que as aportadas pelas inovações tecnológicas em curso, já que "as melhorias na eficiência energética parecem ser insuficientes para estabilizar a poluição gerada pelo setor de transporte (EUROPEAN..., 2007, apud GAIGNÉ et al., 2012, p. 123).

A possibilidade de redução das emissões poluentes explica, em grande parte, o apoio dos governos e instituições ao adensamento das cidades. Entretanto, alguns críticos da ideia argumentam que estas vantagens energéticas podem não ser efetivas, devido ao efeito da concentração de poluentes (MADUREIRA, 2005).

Outro ponto importante são os efeitos negativos das políticas de incentivo à densificação, que podem provocar a realocação de empresas e famílias, uma vez que afetam preços, salários e o valor dos imóveis e aluguéis (MADUREIRA, 2005; GAIGNÉ et al., 2012).

Num contexto metropolitano e de procura de soluções para os problemas apontados na cidade compacta surgiu a proposta de um modelo híbrido, conhecido como "concentração descentralizada ou modelo policêntrico em rede", que se apresenta como "solução relativamente consensual". Trata-se de uma conformação "multinucleada" ou de "uma cidade-região" que reuniria diversos centros autônomos, interligados por transportes públicos (MADUREIRA, 2005, s.p.); cada um destes centros funcionaria como uma pequena cidade compacta - com menor risco de congestionamentos e poluição, menores distâncias as percorrer entre moradia e trabalho. Este modelo parece descrever bem os esforços de compactação em metrópoles e, em especial, a organização atual na região de Paris (SASSEN, 2005) e a proposta para a Grande Paris (ENRIGHT, 2013) - que inclui, entre seus objetivos, os encaminhamentos preconizados pelos defensores desta conformação: 
promoção de espaços multifuncionais; desenvolvimento de pontos focais de articulação de atividades; redução de trajetos e tempo de transporte; integração de modais; desestímulo à circulação de automóveis particulares, redução energética e muitos outros.

Existe, entretanto, uma discussão sobre a orientação estratégica da proposta parisiense que contrapõe um foco predominantemente econômico à busca de um equilíbrio das relações sociais, fator que deve também constituir uma prioridade. Esta discussão se situa na polarização, mas também na interface, entre as ideias de Cidade Global e de Cidade Justa.

\section{Cidade Global: provimento de infraestrutura e gentrificação}

Um dos fatores que tem exercido grande influência na evolução urbana é a globalização, que cria um contexto no qual as cidades entram em competição para atrair novos fluxos econômicos (HARVEY, 1996). Este fenômeno que, até então, vinha sendo estudado principalmente pelo efeito da "neutralização da Geografia", ganhou uma nova perspetiva a partir da introdução do conceito de "Cidade Global" cunhado por Saskia Sassen (2005, p.31). A autora tenta resgatar a importância do lugar, enquanto portador de características essenciais para que as cidades possam ser bem-sucedidas no ambiente global. Ela destaca, entre as características desta Cidade Global, alguns aspetos que já eram explorados no âmbito dos estudos da globalização: a dispersão geográfica, gerada pela possibilidade de levar as operações de grandes empresas para outros países; e a terciarização de parte das funções centrais tradicionais das sedes das empresas, como contabilidade, marketing, departamento legal, etc. Mas ela enfatiza, também, o desenvolvimento de uma economia de aglomeração, possibilitada pela presença de talentos e peritos relativos ao mix de atividades em que as empresas estão envolvidas. Desta forma, quanto mais as empresas terciarizam suas atividades, mais livres ficam para se instalar em cidades onde existirem as condições para o que Sassen chama de "loop informacional" (p. 29). Outra questão importante é a organização destas cidades em redes, articuladas umas às outras, ao mesmo tempo em relação de interdependência e em competição permanente.

Neste ambiente, os objetivos econômicos se tornam prioritários para o poder público local, que passa a focar-se nas necessidades das empresas, incorporando o propósito de garantir 
os fluxos de investimentos (SANTOS, 1988). Sassen (2005) destaca, entretanto, o facto de que as mesmas características que geram a dinâmica global nas cidades concorrem para aumentar a desigualdade local: a grande densidade de talentos e a acirrada competição entre eles valoriza os empregos ligados a determinadas atividades, que contrastam enormemente com aquelas que não fazem parte deste circuito. Os esforços de sobrevivência dos trabalhadores ligados a estas últimas acabam por aumentar a informalidade nos setores a elas relacionados - e a tendência é o surgimento de uma grande desigualdade de salários e oportunidades. Esta desigualdade se acentua dentro de estratégias em que prevalece a imagem da cidade, cujo valor é construído por meio de planos internacionalizados e ação de empreendedores (HARVEY, 1996). Procura-se, muitas vezes, por meio de "revitalizações urbanas", excluir o perfil de população indesejada, o que gera o fenômeno da gentrificação (ARANTES, 2000).

O conceito de gentrificação faz referência ao processo de substituição das classes populares em territórios anteriormente desvalorizados, provocado pelas transformações urbanas que acabam estabelecendo um enobrecimento desses setores das cidades (ARANTES, 2000). Eles se tornam mais atrativos para classes qualificadas (MENDES, 2011), que se apropriam do espaço, levando a uma elevação nos custos de vida, inclusive nos gastos referentes à habitação, com valorização dos imóveis, aluguéis, impostos, entre outros. Assim, "o desenvolvimento imobiliário urbano - a gentrificação em sentido amplo - tornou-se, agora, um motor central da expansão econômica da cidade, um setor central da economia urbana" (SMITH, 2006, p. 85).

Porém, a cidade global também tem o potencial de produzir uma dinâmica local positiva: “Resgatar a geografia dos lugares envolvidos na globalização permite resgatar as pessoas, trabalhadores, comunidades e, mais especificamente, as diferentes culturas de trabalho, outras que a cultura corporativa, envolvidas no trabalho da globalização (SASSEN, 2005, p.32).

Revitalização e gentrificação não são, portanto, fenômenos absolutos, podendo existir de forma dissociada. Para que isso ocorra, é necessário que o objetivo não seja apenas econômico, mas que contemple, também, a questão da vitalidade em si, buscando promover a vida urbana. Neste sentido, é fundamental que haja uma apropriação popular e participativa das áreas de intervenção: a questão principal passa a ser o modelo de 
apropriação, em vez da revitalização em si (JACQUES, 2005). Desta forma, mesmo em um ambiente global é possível "[...] desenvolver categorias como lugar e processo de trabalho", esforço que "traz à tona o facto de que muitos dos recursos necessários para as atividades econômicas globais não serem hipermóveis e estarem, de facto, profundamente implantados no lugar [...] (SASSEN, 2005, p.31).

No projeto para a Grande Paris, estas questões estão em pauta: o frágil equilíbrio gerado pelas forças políticas atuantes pode ser precário para a construção da metrópole. O desafio consiste em criar condições em que se desenvolvam diversidade, democracia e equidade, o tripé de suporte da Cidade Justa, preconizada por Susan Fainstein (2011).

\section{Paris como ponto focal de redes metroviária e ferroviária}

\section{radiais}

Na região de Paris, ao longo dos séculos XIX e XX, os sistemas de metrô urbano e de trens se desenvolveram de forma bastante autônoma, por decisão da prefeitura local, que adotou este direcionamento com a intenção de limitar o espraiamento da cidade (GERONDEAU, 2003 apud MAYER; TREVIEN, 2017). Por outro lado, o centro urbano foi por muito tempo o ponto focal das linhas férreas do país, que ainda convergem prioritariamente para esta região, mas também do sistema metroviário, que se desenvolveu de forma radial.

Entre 1883 e 1921, o sistema de trens funcionou por meio de contratos do governo com as companhias. A sua unificação e transformação em sistema público - SNCF - só ocorreu em 1938 (ZORZO, 2009). Cada linha tinha como destino sua própria estação de término situação que perdurou mesmo depois da unificação (GERONDEAU, 2003 apud MAYER; TREVIEN, 2017). A comunicação entre as várias estações ferroviárias se fazia por meio do metrô - de maneira que o trajeto entre um subúrbio e outro envolvia uma viagem de trem, uma conexão por meio de metrô e outra viagem de trem (MAYER; TREVIEN, 2017). Assim, o sistema de metrô, implantado de forma eficiente e densa desde o século XIX, teve um papel importante na articulação dos subúrbios - não só interligando as linhas férreas, mas também conectando-os efetivamente ao centro (CASTRO, 2007). 
A partir dos anos 1930 - época da qual data a primeira proposta de organização do crescimento urbano, apenas parcialmente aplicada (BELKIND, 2013) - ocorreu tanto a conexão entre os sistemas férreos, por meio da extensão das linhas (MAYER; TREVIEN, 2017), quanto a unificação das redes de metrô - padronizando as operações e infraestruturas (BERTON, OSSADZOW, FILLOLES, 2007), com desdobramentos e novas extensões nos subúrbios já em 1949.

A partir de então, o Estado francês adotou um direcionamento centralizador (BELKIND, 2013). Nos anos 1960, um primeiro plano, efetivamente focado no transporte dos subúrbios na região de Paris - o Plan d'aménagement et d'organisation générale (PADOG) - procurou restringir o desenvolvimento urbano às áreas já edificadas, que seriam reorganizadas. 0 centro foi considerado saturado e o objetivo era chegar a um equilíbrio, desenvolvendo outras regiões, que eram então tidas como praticamente desertas (MAYER; TREVIEN, 2017). Neste processo, a infraestrutura de transporte assumiu papel de destaque e o plano implementou soluções decorrentes de discussões realizadas em anos precedentes, incluindo a proposta de uma rede de túneis interligando linhas isoladas de trens de subúrbio. A ideia, que já fazia parte de um plano da Compagnie du chemin de fer métropolitain de Paris, de 1936, foi, então, retomada. Embora o seu lançamento efetivo só se tenha dado com o plano SDAURP, em 1965, a Rede Express Nacional (RER) passou a ser implantada desde o ano 1962, com articulação em larga escala até 1977 e ampliações subsequentes - processo ainda em curso na atualidade (MAYER; TREVIEN, 2017).

O foco das políticas públicas no transporte coletivo na região parisiense se acentuou no final da década de 1970. Nesta ocasião, o transporte individual, crescente desde os anos 1920, passou a ser considerado, no debate político, como um problema, o que situou a questão do ponto de vista social e urbano (CASTRO, 2007).

Desde então, o transporte público tem sido objeto de investimentos e políticas específicas. Os recursos que configuram a situação atual na região metropolitana de Paris são resumidos da seguinte forma:

A grande rede de transportes públicos conta com uma densa trama de serviços interconectados (coordenados por STIF) que cobrem a cidade e parte de sua periferia: 14 linhas de Metrô ( 2 delas conformam uma Circular) com 17 trajetos na periferia; 5 linhas da Rede do Expresso Regional RER, que cruzam a cidade em todas as direções e a vinculam com a região; 3 Tranvias, uma circular com a $2 \underline{a}$ etapa (de três) em finalização e outras duas tangenciais ao Periférico; 57 linhas 
diurnas de ônibus, com alguns trajetos fora da cidade e 37 linhas noturnas, todas partem do centro, com trajetos exteriores à cidade; 750 estações de bicicletas de livre uso (Velib); um sistema de autos elétricos de livre uso (Autolib) em instalação e com inauguração próxima (BERJMAN,2011, p.3)

Observa-se, entretanto, que a dinâmica espacial da metrópole tem feito com que algumas regiões concentrem mais empregos do que habitantes e/ou algumas categorias de empregos muito específicas, gerando importante demanda em termos de deslocamentos. As políticas de transporte não parecem ter previsto nem acompanhado as demandas emergentes, negligenciando a evolução dos modos de vida e as necessidades de deslocamento impostas, em parte, pelo processo de dispersão dos empregos. Desta forma, fala-se de uma "disjunção espacial entre as redes de transporte, a localização dos empregos e os ativos, na França" (BORDEAU-LEPAGE, 2013, p. 419).

\section{O Grand Paris Express: a colocação do projeto em pauta e}

\section{integração na agenda}

No contexto do transporte público de Paris, a rede de metrô consiste numa trama de eixos centrípetos. A necessidade de circulação perimetral é contemplada por redes de ônibus, cuja velocidade comercial, entretanto, é limitada por congestionamentos frequentes. Umas das estratégias em curso para lidar com este problema consiste na construção de linhas circulares de bondes - os "auto-elétricos" citados por Berjman (2011), interligando os eixos de metrô pré-existentes (CASTRO, 2007). Esta circulação em torno de Paris possibilita uma interligação entre as centralidades periféricas que se impõem e a ideia de reforçar esta possibilidade é que está na origem do GPE.

A criação de um sistema de transportes de contorno subterrâneo da capital pela periferia já havia sido evocada várias vezes mas, somente em 1994, um primeiro projeto circuncêntrico, chamado Orbital, foi efetivamente esboçado. Em julho de 2006, a ideia saiu das gavetas, constituindo-se como um consenso entre as grandes orientações políticas, porém, a partir de perspetivas diferentes: a visão do Estado e a visão da Região.

A primeira proposta relacionada ao tema foi lançada no final de 2007 , pelo presidente do Conselho da Região lle de France, que apresentou a visão de um sistema de metrô 
automático contornando Paris - o Arc Express - projeto que vinha sendo desenvolvido pelo Sindicato de Transportes de lle de France (STIF) (BERJMAN, 2011). O Estado, por sua vez, organizou em 2008, um processo que ficou conhecido como a "Consulta Internacional da Grande Paris", buscando propostas de desenvolvimento urbano e planejamento do território da região da capital, com o horizonte de 2050, ou seja, prospeções sobre o futuro da metrópole (BELKIND, 2013; BERJMAN, 2011). O ponto de partida consistiu em estudos contidos no Plano Diretor da Região de Ile de France (SDRIF) (BERJMAN, 2011). Por meio da análise dos múltiplos dossiers submetidos a uma chamada internacional, foram selecionadas dez equipas, envolvendo grandes nomes da arquitetura e urbanismo mundial ${ }^{2}$, para produzir propostas de desenvolvimento urbano e planejamento do território da região da capital. A discussão se concentrou nos sistemas urbanos e nas infraestruturas, a partir de abordagens bem diversas (BERJMAN, 2011; BELKIND, 2013).

Em abril de 2009, foi anunciada pelo presidente Nicolas Sarkosy a criação do projeto de rede pública que ficou conhecido como "Double Rocade" ou "Grand Huit" (BERJMAN, 2011). O foco estratégico foi claramente colocado no discurso de Sarkosy (2009 apud BORDEAULEPAGE, 2013, p. 407), que reafirmou a necessidade de inserção na competição global.

Em seguida, foi promulgada a Lei de 2010 sobre o Grand Paris Express (lei de 3 junho de 2010), que criou uma entidade pública dedicada à construção desta nova rede: a Sociedade da Grande Paris ou SGP. A lei outorgou à SGP a responsabilidade de desenvolvimento de empreendimentos imobiliários nos cinquenta hectares nos arredores de cada uma das estações a serem construídas, limitando, desta forma, a ação dos municípios e da região (BERJMAN, 2011), indo no sentido oposto do processo de descentralização política francesa, que havia ampliado a competência destas instâncias.

Conforme estabelecido pela Lei, o Estado francês organizou um extenso debate público sobre o projeto. Ao mesmo tempo, a região lle de France organizou debates públicos sobre a sua proposta, o Arc Express. Os debates sobre os méritos dos dois projetos se estenderam entre 2010 e 2011, ao longo de 4 meses, durante os quais foram realizadas 67 reuniões

\footnotetext{
${ }^{2}$ Roland Castro - Silvia Casi, Atelier Castro-Denissof-Casi / Finn Geipel +Giulia Andi, LIN / Antoine Grumbach \& Associés / Djamel Klouche, l'AUC / Yves Lion, Groupe Descartes / Winy Maas, MVRDV avec ACS et AAF / Jean Nouvel [AJN], Jean-Marie Duthilleul [AREP], Michel Cantal-Dupart [ACD] / Atelier Christian de Portzamparc / Richard Rogers - Mike Davies, Rogers Stirk Harbour + Partners, LSE, Arup / Bernardo Secchi et Paola Vigano, Studio 11.
} 
públicas (AUZENNET, 2012), no "maior processo de planejamento participativo na história da França" (BELKIND, 2013. p. 1). A publicidade dada à discussão exerceu uma pressão política que levou a um compromisso entre o Estado Francês e a Região de lle de France e à assinatura de um protocolo de acordo, lançando oficialmente o Grand Paris Express (GPE) (BELKIND, 2013). Em maio de 2011, o Conselho da SGP aprovou por unanimidade o esquema do conjunto do GPE que, em 24 de agosto de 2011, foi aprovado por decreto (AUZENNET, 2012). Sob a pressão da Região, uma revisão do projeto em 2013 passou a inserir um trecho a leste, com o objetivo de atender à periferia mais próxima do lado oriental, antes considerado não prioritário - uma "rede complementar estruturante", até então, com pouca probabilidade de ser construído (BEAUCIRE, DREVELLE, 2013) (ver figura 1). Este trecho - a linha 15 Leste - possibilita a integração de comunidades com menor desempenho econômico e permite uma melhor inserção de seus habitantes às áreas mais favorecidas, suprindo, desta forma, demandas de equidade social.
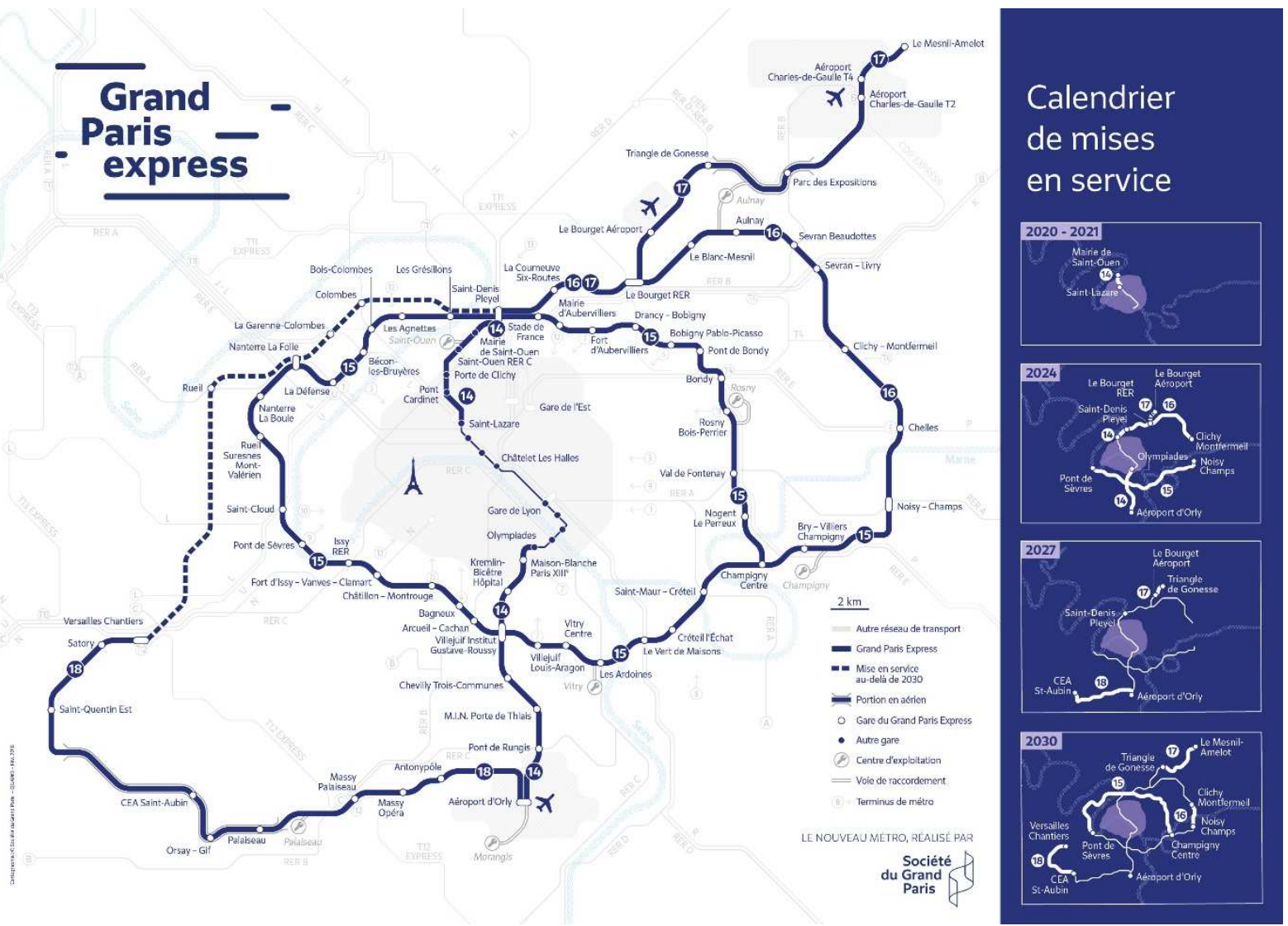

Figura 1: Linhas e estações, com a previsão inicial das obras do Grand Paris Express. Fonte: https://www.societedugrandparis.fr/gpe/carte 
A análise de todo o processo de configuração do empreendimento revela uma afirmação do papel do Estado no planejamento da região da capital e denota uma nítida polarização que Belkind (2013) situa entre o foco econômico - a Cidade Global - e o foco social - a Cidade Justa.

O objetivo do projeto do Estado era conectar os principais polos geradores de emprego entre si e com o mundo, reforçando a posição de Paris como centro econômico global, catalisador de investimentos imobiliários. Dentro dos rankings internacionais que utilizam diferentes critérios para identificar as metrópoles globais mais poderosas, Paris está bem colocada - em geral logo atrás de Nova York e Londres. Porém, o nível de investimentos em seu território vem regredindo, face à competição de algumas cidades europeias e asiáticas (BORDEAU-LEPAGE, 2013), o que justifica os esforços para se contrapor a esta tendência.

Por sua vez, os agentes políticos atuantes no âmbito da governança da região de lle de France, que abriga Paris, buscavam uma solução para atender às necessidades da população de seu território e melhorar as condições de transporte. Sua proposta foi desenvolvida com o objetivo de reforçar a conexão de comunidades isoladas, com destaque para áreas do Nordeste, onde as ofertas de emprego são transitórias e dispersas. Procurava-se, assim, equilibrar o acesso ao emprego, treinamento e outras oportunidades (BELKIND, 2013; BORDEAU-LEPAGE, 2013)

O confronto das propostas Estado x Região levantou, portanto, questões sobre o bem-estar social, habitação e transporte, o crescimento econômico, a projeção internacional da cidade no mundo, o acesso ao emprego, a democratização urbana e a qualidade ambiental (BORDEAU-LEPAGE, 2013, p. 405). Todo o processo de negociação entre as duas instâncias, tem gerado a emergência de uma governança envolvendo diversos atores, com visões díspares (BELKIND, 2013). Eles atuam em diversas camadas, numa condição que gera questões de grande complexidade e difícil gestão (CHANG, 2016).

Apesar da dificuldade de conciliação de tantos parâmetros e visões, a proposta parte de princípios que se articulam em torno da busca da sustentabilidade, tanto na fase de sua implantação quanto na fase de utilização da estrutura construída. 


\section{Sustentabilidade na fase de implantação}

\subsection{Aquecimento da economia local e inserção social}

A realização do GPE, com despesas inicialmente previstas em 20,5 bilhões de euros (AUZANNET, 2012), representou, na época de seu lançamento, um manancial inesperado para a economia da região. A necessidade de reativação do desenvolvimento econômico foi um aspeto que, com certeza, contribuiu para a viabilização da construção de uma obra de tal envergadura e dos investimentos necessários para tanto (JLL, 2016). Adicionalmente, o projeto pode reposicionar a França à frente do setor de transportes. Além da disputa pela operação das linhas ( licitação da qual participam, a Régie Autonome des Transports Parisiens (RATP) - que atualmente tem o monopólio do transporte em Paris - a Transdev, filial da Caisse des Dépôts e a Keolis, filial da SNCF), outro contrato importante é o do fornecimento do material rodante (CHATELAIN, 2017), assinado com a francesa Alston, em 2018, para o fornecimento dos novos vagões para as linhas 15, 16 e 17).

A realização do GPE também trouxe uma lufada de oxigênio ao setor da construção civil, quase exangue depois de uma década pobre em investimentos em infraestrutura. Os primeiros beneficiários deste aquecimento do mercado foram os escritórios de engenharia e arquitetura, seguidos pelas empresas construtoras. Além das equipas que trabalham diretamente nos projetos das novas estações de metrô, outras mais se encarregam de assegurar a interconexão da nova rede com os transportes preexistentes. Todas as maiores empresas francesas do ramo estão envolvidas neste projeto, seja nas infraestruturas pesadas (Vinci, Bouygues, Eiffage), seja na construção civil (Fayat, NGE, Leon Grosse). O objetivo inicial era inaugurar as primeiras linhas a partir de 2022 (linha 15 Sul) e, em seguida, a linha 16, que irriga a região de Seine-Saint-Denis, onde estará situada uma parte importante das instalações olímpicas (YVIN, 2017).

Por outro lado, trata-se de uma ocasião rara de visibilidade no longo prazo, que permite consolidar as empresas. Com contratos fechados ou previstos para os próximos vinte anos, elas podem investir na formação de mão de obra especializada. Existem ainda oportunidades para novos atores, em particular as pequenas e médias empresas que, conforme estabelecido nos contratos, deverão ser responsáveis, no mínimo, por $20 \%$ das obras (YVIN, 2017). 
Em matéria de geração de emprego, os objetivos são também ambiciosos: 10.000 a 15.000 novos empregos diretos por ano (YVIN, 2017). Os critérios de atribuição dos contratos são, tradicionalmente, a qualidade técnica, o preço, o custo de manutenção e o prazo de execução. Mas foi também incluída uma cláusula de inserção, garantindo que uma parte das horas de trabalho geradas seja ocupada por pessoas desempregadas, jovens, portadores de deficiência. Trata-se de um dispositivo já utilizado na maioria das obras públicas francesas, com objetivo de combate ao desemprego e à exclusão - e, no caso presente, de estímulo à dinâmica social do território regional. Por outro lado, estima-se, no longo prazo, a criação de 115.000 a 315.000 vagas de emprego no setor de obras públicas (JLL, 2016).

Outro efeito esperado, no longo prazo, é a afirmação do posicionamento internacional das empresas francesas, uma vez que a complexidade das obras exige uma especialização técnica, afirmando o savoir-faire francês nos campos da construção subterrânea e renovação do sistema urbano (YVIN, 2017).

A nova rede atravessará zonas urbanas muito densas, em alguns casos, com o subsolo já ocupado, além de terrenos geologicamente complexos, exigindo a aplicação de técnicas de ponta para a execução, controle e monitoramento da execução da obra e de seus impactos. Serão necessários vários tipos de tratamentos de solo e de infraestruturas como paredes diafragmas, jet grouting, injeções, micro estacas, congelamento do solo... (RENAUD; EL KAIDI, 2017). Além disso, destaca-se, como desafio, a exatidão na implantação relativa entre os canteiros, que constituem elementos de infraestrutura construídos simultaneamente por meio de diversas técnicas, exigindo uma interconexão perfeita (RENAUD; EL KAIDI, 2017).

A fase de construção coloca, ainda, outras demandas que representam desafios: integração numa lógica de desenvolvimento sustentável, o respeito pelos moradores, tráfego e bairros atravessados pelas obras e a transparência na comunicação com os moradores e comerciantes afetados (YVIN, 2017, p.40). Várias medidas foram previstas para reduzir os impactos negativos ao mínimo possível, ao mesmo tempo em foram lançados diversos concursos de ideias buscando alternativas sustentáveis. Estas iniciativas resultam hoje em experiências que estão sendo implementadas para testar outras maneiras de suavizar o impacto das obras nos comércios e serviços vizinhos, nas condições de circulação perto das obras, bem como para administrar o solo e materiais resultantes das escavações (YVIN, 2017; CHATELAIN, 2017). 


\subsection{Identidade de rede e inserção no tecido urbano}

O conceito de projeto das estações foi baseado na busca por uma identidade de rede, com a qual os usuários possam se relacionar. Para viabilizar esta ideia e ao mesmo tempo assegurar a inserção nos tecidos urbanos preexistentes a SGP optou por confiar a intervenção a arquitetos diferentes, determinando, entretanto, uma linguagem em comum, para articular a lógica urbana com os objetivos de eficiência dos transportes. Para isso, foi elaborada uma "Carta da arquitetura das novas estações", que define as diretrizes de projeto, estabelecendo princípios de conforto, fluidez, materiais, linha de móveis e equipamentos, orientações de iluminação e acústica (BECHERAND, 2017).

A partir daí, foi realizado o concurso que permitiu escolher os arquitetos para a realização das novas estações. Os projetos estão hoje em pleno andamento e mobilizam um grande número de arquitetos (sempre associados a grandes escritórios de engenharia especializados em transportes ferroviários) - alguns dos quais realizam os projetos de várias estações. ${ }^{3}$ Trinta e sete equipas estão envolvidas nesta oportunidade de lançar grandes reflexões sobre a arquitetura. A partir das diretrizes pré-definidas, cada estação é pensada no seu contexto específico e dá origem a uma resposta arquitetônica singular. A unidade da rede terá sua base na diversidade dos edifícios e na identidade comum de seu mobiliário e da comunicação visual (BECHERAND, 2017).

\subsection{Instrumentos de promoção das prioridades locais: os CDT}

As políticas públicas da França têm demonstrado, ao longo dos anos, grande preocupação com a articulação dos sistemas de transporte com as questões sociais. Nesta tradição, uma inovação significativa trazida pelo processo de implementação do GPE foi a criação dos Contratos de Desenvolvimento Territorial (Contrat de Développement Territorial - CDT), um mecanismo de distribuição de responsabilidade, incorporando propostas organizadas por autoridades locais e empresas parceiras. Embora ainda em fase de implantação, espera-se que os CDTs venham a viabilizar a materialização das demandas locais, condição que Latour

\footnotetext{
${ }^{3}$ Entre outros, Valode e Pistre (estações Vert de Maison, Pont de Rungis, Les Ardoines) Brunet e Saulnier (Issy) Philipe Gazeau (Vanves Clamart) Marc Barani (Bagneux), Agence Duthilheul (Noisy Champs, Pont de Sevres, Sevran Beaudottes e Sevran Livry), Elizabeth de Portzamparc (Le Bourget), Atelier Schall (Chelles-Gournay), Dominique Perrault (Villejuif)...
} 
(1996, 2005, apud BELKIND, 2013) considera imprescindível para o sucesso de democracia metropolitana.

Os CDTs são acordos contratuais entre o Estado e as municipalidades que vão ser servidas pela nova rede, com o propósito de estabelecer metas no que diz respeito ao desenvolvimento econômico e habitacional, bem como à disponibilização de serviços públicos. Embora tenham sido recebidos com relutância pelos políticos locais - que temiam uma recentralização do poder do Estado nas tomadas de decisão - na maioria das vezes, estes têm representado uma oportunidade para as municipalidades promoverem as prioridades locais (GALLEZ, 2014). Os debates continuam ainda hoje, em busca da definição precisa do modo de governo da nova metrópole e da delimitação exata da competência das diferentes instâncias.

\section{Sustentabilidade na fase de uso}

\subsection{A questão ambiental}

Qualquer discussão sobre sustentabilidade ambiental passa pela análise da questão dos transportes em razão da grande dependência do setor em relação ao petróleo e de seu grande peso nas emissões de carbono, propiciando mudanças climáticas antropogênicas (SCHWANEN, 2016, GAIGNÈ, RIOU e THISSE, 2012).

No GPE, a inovação energética e a preocupação com o ambiente estão no cerne do projeto: a expectativa é de que sua implantação seja capaz de promover uma redução de 27,6 Mt de $\mathrm{CO}_{2}$ entre 2010 e 2050 (ANDRIOSOPOULOS, SILVESTRE, 2017). Por um lado, a nova rede deve contribuir para a redução do uso de automóveis, por meio da melhoria do acesso ao transporte público. Por outro, uma redução de $30 \%$ do consumo elétrico dos trens será viabilizada por um sistema de recuperação da energia liberada durante a frenagem dos trens para reinjeção e utilização na aceleração de outros trens (CATHELAIN, 2017, p.44).

Entretanto, o problema de utilização de automóveis não se resolve somente com a construção da rede - é ainda necessário que parisienses adotem os transportes públicos (GONGUET, 2017). Atualmente, as viagens diárias em transporte em comum envolvem 
pouco mais de oito milhões de passageiros e, em automóvel, vinte milhões. As previsões são de que em 2030, se toda a rede prevista for construída, entre 9,7 (previsões mais conservadoras) e 11 milhões de viagens (previsões mais otimistas) poderão ser feitas em transporte público. Porém, a quantidade de viagens em automóvel não diminuiria significativamente. Assim, a forma pela qual o projeto pode efetivamente aliviar o trânsito é reduzindo os tempos de trajeto, principalmente nas comunas mais populosas (GONGUET, 2017).

\subsection{Acessibilidade}

Além de reduzir o tempo de transporte, a ambição da SGP é transformá-lo em tempo útil, propício ao trabalho ou ao lazer, graças a uma potente rede de conexão internet, atingindo todos os recantos dos volumes criados. Esta dimensão de "acessibilidade virtual" é uma parte importante do programa para os espaços de toda a nova infraestrutura (YVIN, 2017).

Outra evolução em relação à rede existente é a acessibilidade: ao contrário das estações antigas, que não foram imaginadas para pessoas deficientes, as novas estações não deverão apresentar dificuldades para as pessoas com mobilidade reduzida. Na França, a obrigatoriedade de acessibilidade dos equipamentos públicos foi formalizada pela lei de 11 de fevereiro de 2005, e não se resumiu aos portadores de deficiência física. Os objetivos de acessibilidade atuais são vastos: integram também os deficientes mentais e, mais globalmente, todos os usuários. A proposta do GPE é simplificar os espaços, de maneira que eles sejam facilmente assimilados - o que é garantia de fluidez de circulação e otimização da intermodalidade de forma eficiente, confortável e segura. Para isso, o projeto prevê também um planejamento compatível nas proximidades das estações (THORIN, 2017).

A conceituação das novas estações se baseia, de maneira clássica, num objetivo de eficiência de transporte de passageiros: garantir que os percursos sejam simples e evidentes, e que sejam realizados em condições de segurança e de acessibilidade, Trata-se de construir uma cidade mais conectada, mas também mais humana (THORIN, 2017). Por outro lado, a ideia é que as estações sejam mais do que uma porta de entrada para a nova rede de transportes, promovendo o desenvolvimento das regiões em que serão implantadas. 
As novas estações pretendem, então, ser um "vetor de vida ao serviço dos viajantes e dos habitantes" (THORIN, 2017, p.55), espaços eficientes, facilitando o acesso aos outros modos de transporte, inclusive os não motorizados. Integradas no seu contexto e estabelecidas como serviços públicos, incorporando comércios e serviços, atendendo às demandas locais, estas são propostas como equipamentos geradores de uma nova dinâmica para uma cidade compacta, mista e sustentável.

Cerca de $140 \mathrm{~km}^{2}$ serão impactados diretamente pelas estações e diversos projetos urbanos já estão sendo apresentados para os bairros em que serão construídas as novas estações, integrando equipamentos públicos, escritórios e habitações (YVIN, 2017).

A relação com o entorno é um contraste marcante com a atual rede de metrôs parisienses, na qual as estações são subterraneas e pouco perceptíveis na superfície, com longos corredores conduzindo a múltiplos pontos de entrada e saída nas calçadas. As estações do GPE deverão, ainda, se tornar pontos de referência, com presença marcante no nível da cidade, embora a rede seja implantada bem mais profundamente que o metrô atual.

\subsection{Em busca de uma cidade global e justa}

Na construção das novas linhas de transporte, as transformações urbanas não constituem um mero corolário, mas uma parte integrante - e fundamental - dos objetivos. Conforme já visto, é notório o empenho do Estado Francês em apoiar a competitividade econômica dos territórios (JLL, 2016; FRANÇA, 2010, SALAT; BOURDIC, 2016). O investimento nas infraestruturas dos transportes não é uma forma nova de tentar superar uma crise econômica (HARVEY, 2001; PATERSON, 2014 apud SCHWANEN, 2016) e, no caso da Grande Paris, fundamentou-se na perceção de que é possível atrair capital e criar empregos aumentando a eficiência (SCHWANEN, 2016). Outro objetivo é atender às demandas de integração das pequenas comunidades, que são mais frágeis em termos de desempenho econômico e não constituem prioridade, do ponto de vista de posicionamento global - mas que demandam acesso ao emprego, treinamento e outras oportunidades.

A região a oeste de Paris concentra uma grande quantidade dos empregos e ela é privilegiada pelo projeto do Estado tal como proposto em 2011, em sua alça Oeste. Este favorecimento, que acentua as desigualdades de acesso ao emprego em relação à região 
leste, foi colocado em questão, levando a uma revisão do projeto, em 2013. A inclusão de um trecho extra a leste, entre os limites de Paris e o traçado mais oriental do projeto inicial, reequilibrou a proposta, atendendo a comunidades desfavorecidas como Bobigny ou Bondy (BEAUCIRE, DREVELLE, 2013). Assim, o novo trecho tem o potencial de propiciar uma redução (de $36 \%$ para $10 \%$ ) na desigualdade de acesso ao emprego entre oeste/leste, favorecendo a integração das comunas mais frágeis ao mercado de trabalho regional (BEAUCIRE, DREVELLE 2013). Entretanto, sua construção foi adiada em cinco anos no cronograma de execução mais recente (POUTHIER MOUTARDE, 2018).

Existem, ainda, outros riscos quanto às repercussões da nova rede de transportes na estrutura do espaço, considerando que deverá promover mudanças diretas em vários setores do território urbano, com evidentes consequências no mercado imobiliário: uma verdadeira "revolução imobiliária" (YVIN, 2017). Estas mudanças na dinâmica urbana e o adensamento de áreas são capazes de provocar impactos diretos em preços, salários e rendas de terra, forçando famílias a se mudar para outros locais (GAIGNÉ, RIOU e THISSE, 2012). A análise de outras intervenções importantes no sistema de transporte na região metropolitana - como a construção do RER - revela a instalação de famílias com maior qualificação nas proximidades das estações (MAYER e TREVIEN, 2016). Este processo de gentrificação associado a grandes projetos urbanos reforça, então, a necessidade de políticas públicas para a correção das distorções.

Em relação ao GPE, parece existir uma preocupação institucional com esta questão. Inicialmente, os já mencionados Contratos de Desenvolvimento Territorial se colocam como instrumento voltado para atendimento das demandas locais. Além disso, está sendo construída uma articulação com um duplo foco: por um lado, procura-se efetivamente garantir o desenvolvimento das áreas com maior potencial; mas, por outro, existe a intenção de auxiliar as áreas que enfrentam dificuldades.

Um estudo feito pelo Grupo Caisse des Dépôts, em parceria com o Instituto de Morfologias Urbanas (SALAT; BOURDIC, 2016), demonstra estas perspetivas, permitindo identificar a dinâmica atual e antever tendências econômicas de cada local. O estudo considera a criação de novas urbanidades, analisando a conexão entre as estações do GPE e as densidades habitacionais e de emprego. Duas classificações diferentes são propostas em relação aos novos centros criados pelas estações: uma delas as situa a partir de sua centralidade na 
rede, qualidade urbana e dinâmicas de desenvolvimento, de forma a identificar áreas com maior potencial de desenvolvimento econômico. A outra classificação, por sua vez, as situa a partir do dinamismo demográfico, do potencial de acesso aos empregos, integração e mix de atividades geradas. O objetivo, neste caso, é identificar áreas mais frágeis e encontrar mecanismos para auxiliá-las. Desta forma, não parece ser a distância entre a habitação e o local de trabalho que prejudica a empregabilidade das pessoas, mas a ausência de meios de transporte eficaz para transpô-la (WILSON 1987; PUGH, 1998 apud BEAUCIRE, DREVELLE, 2013) e o projeto tem um grande potencial no sentido de reduzir desigualdades.

\section{Considerações finais}

A nova metrópole que se configura parece aproximar-se de um modelo policêntrico de cidade, permitindo a estruturação de concentrações urbanas bem conectadas de forma eficiente, reduzindo os gastos energéticos. Conforme preconiza Castells (1999), "o espaço organiza o tempo" nas sociedades em rede (p.467) e a articulação proposta pelo GPE promete uma profunda reorganização do tempo, diminuindo congestionamentos, propiciando uma redução de trajeto entre residência e trabalho, uma redução da utilização de veículos privados. A infraestrutura urbana existente poderá ser rentabilizada em termos não só de circulação viária, mas também no que diz respeito a equipamentos sociais, redes de saneamento, energia e outras.

Com relação à justiça social, os investimentos do Grand Paris Express trazem novas possibilidades para redução das desigualdades: de uma parte, da periferia com relação ao centro de Paris, que apresenta tradicionalmente um aumento de oferta de emprego bem superior; de outra parte, entre a região oeste e a leste - onde a habitação social é mais presente, as comunidades sofrem com um nível de desemprego mais alto e os imóveis são mais desvalorizados. Considerando, ainda, que o setor oeste da cidade possui maior quantidade e qualidade de empregos, a facilidade de transporte pode trazer novas oportunidades de acesso para os habitantes da região leste. Além disso, a integração social que se pretende criar no entorno das novas estações vai com certeza promover novas 
dinâmicas, capazes de gerar empregos e estimular negócios, alimentando a imagem de cidade eficiente e atratriva, em nível global.

O empreendimento também foi, e continua sendo, responsável pelo reaquecimento da economia francesa, gerando empregos e consolidando competências, a partir de uma atuação das empresas envolvidas em projetos e execução e seus desdobramentos.

Existem "efeitos colaterais" possíveis, como a gentrificação (ENRIGHT, 2013), ou o desequilíbrio entre as regiões, mas existem também dispositivos de combate a estes riscos, tais como as políticas públicas existentes e seus múltiplos recursos - com destaque para os Contratos de Desenvolvimento Territorial - além de iniciativas institucionais no sentido de entender os possíveis desdobramentos do projeto, como o estudo do Grupo Caisse des Dépôts (SALAT; BOURDIC, 2016). Outro exemplo é o esforço que tem sido feito no sentido de democratização das tarifas de transporte que, a partir de primeiro de setembro de 2015, foram unificadas para a ciculação nas cinco zonas da região parisiense (o sistema anterior impunha uma tarifação mais alta aos usuários de zonas mais afastadas, que eram duplamente penalizados pelo fato de estarem mais distantes).

Por outro lado, existem riscos do ponto de vista da materialização técnico-econômica e política do projeto, que parecem ser os mais iminentes. A primeira questão que se coloca é relativa à governança. De acordo com Faure (2018) as atribuições de responsabilidades não são sempre compatíveis com as competências e capacidades: o Estado, ao qual a SGP está diretamente ligada, não teria controle sobre os riscos financeiros e a SGP seria "muito pequena para sua missão."

Outra questão que se coloca diz respeito ao cronograma das obras e seu financiamento. As primeiras escavações necessárias para a realização da linha 15 começaram em 2016. Atualmente, o ritmo está se incrementando: já estavam ativos no princípio de 2017 os três primeiros canteiros da nova rede, com as primeiras intervenções ao sul da capital francesa. Em 2017, mais de 40 frentes de obra foram iniciadas na linha 15 Sul (BONTINCK, 2017) e o primeiro tunnelier (equipamento gigantesco de escavação de túneis) começou a escavação em Champigny-sur-Marne (Val-de-Marne), em abril de 2018. A previsão (YVIN, 2017) era de que, em 2018, todas as linhas do $\operatorname{GPE}(14,15,16,17$ e 18) estivessem em obras. Entretanto, o projeto tem enfrentado problemas técnicos, orçamentários e conjunturais. 
Do ponto de vista técnico, surgiram imprevistos na escavação de túneis, que foram desde a dificuldade na contratação de Tunneliers na quantidade necessária, até questões geotécnicas, como a presença de argila verde, excessivamente plástica. As novas previsões estimam que, na melhor das hipóteses, a linha 15 entrará em funcionamento em 2022, com 2 anos de atraso_(SCHWARZBACH, 2016)

Por outro lado, existe um questionamento sobre a viabilidade financeira da execução do projeto dentro dos prazos inicialmente estabelecidos. Em setembro de 2017, o prefeito da Região de Ile de france, Michel Cabot, recomendou ao governo adiar uma grande parte das linhas para depois das Olimpíadas, temendo o superfaturamento das obras. Com a perspectiva das Olimpíadas de 2024 em Paris e a necessidade de realização dos investimentos em infraestrutura comprometidos, a relação oferta/demanda de empresas para realização dos serviços sofreu uma completa alteração e os preços para as obras subiram em 20 a 30\% nos últimos 5 anos (DAMOUR, 2018). ${ }^{4} \mathrm{~A}$ situação se agravou quando o primeiro ministro francês apresentou um relatório elaborado pela Cours de Comptes (equivalente ao Tribunal de Contas), publicado em 17 janeiro de 2018, sobre os desvios financeiros do projeto. A previsão de gastos era de 20,5 bilhões de euros (AUZANNET, 2012) inicialmente em 2008 e de acordo com este relatório, passou para mais de 38,48 bilhões (DAMOUR, 2018). Este fato se deve a alterações no projeto, mas, também, a avaliações equivocadas e provisões de risco subestimadas pelo SGP. Adicionalmente, os custos financeiros relativos a empréstimos para o financiamento da construção podem quadruplicar o valor inicial previsto (DAMOUR, 2018).

Em 22 de fevereiro de 2018, um novo calendário foi apresentado pelo governo, que manteve a previsão de construção do projeto completo, mas reconfigurou o cronograma de execução das obras, com o adiamento da construção de algumas linhas (POUTHIER MOUTARDE, 2018).

$\mathrm{Na}$ justificativa do adiamento, o governo faz referência às dificuldades técnicas e financeiras, mas também à necessidade de formação de recursos humanos suplementares para atender à demanda, que corresponde a quatro vezes o volume usual de obras da

\footnotetext{
${ }^{4}$ Estes dados contrastam com os relativos à construção do Crossrail, que se manteve dentro dos prazos e custos - apesar de Londres também ter recebido os Jogos Olimpicos em 2012 (THE SKELETON..., 2017)
} 
região de Ile de France. Assim, algumas linhas vão sofrer atrasos que variam de 2 a 6 anos. Entre as obras adiadas, destaca-se o trecho da linha 15 Leste, na seção entre Saint-Denis Pleyel-Rosny Bois Perrier (POUTHIER MOUTARDE, 2018), isto é, o trecho que, segundo Beaucire e Drevelle (2013), é fundamental para o equilíbrio da desigualdade entre as regiões. O adiamento das obras também tem implicações para os investimentos das comunas - em termos de compromissos assumidos em relação à construção de habitação e estruturas urbanas ligadas ao projeto (DAMOUR, 2018).

Alguns dos benefícios esperados do projeto - como disponibilização de empregos, movimentação da economia, visibilidade global da cidade - estão sendo complementados pelas obras de infraestrutura para os Jogos Olímpicos. Porém, do ponto de vista da eficiência energética, da organização do trânsito e da redução de trajetos - e sobretudo do ponto de vista de equilíbrio de oportunidades entre as regiões mais frágeis e as mais sólidas - as previsões são de que os benefícios sejam realmente adiados.

Numa perspetiva de gestão, o novo cronograma parece ser mais realista, face aos problemas identificados. O ponto crítico, na verdade, parece ser as projeções iniciais, que geraram expectativas de difícil realização, mas que tiveram suporte institucional pelo facto de atenderem a objetivos políticos - como fortalecer a candidatura de Paris a sede dos Jogos Olímpicos - negligenciando riscos e subestimando custos. Nesta ótica, considerando também o adiamento do trecho da linha 15 Leste, a busca da cidade global e a lógica neoliberal dos grandes projetos de urbanismo (ENRIGHT, 2013) parecem estar prevalecendo sobre a construção da cidade justa no GPE. Entretanto, apesar dos riscos apontados, existem possibilidades de compatibilização entre as duas visões, que podem ser complementares.

Dentro das diversas matrizes de discursos sobre a sustentabilidade urbana que Acselrad (1999) identifica, existem dois modelos de uma proposta que ele chama de "reprodução adaptativa das estruturas urbanas" - um deles baseado na eficiência e o outro na equidade. Ambos os modelos partem de uma perspetiva política na qual a "base técnico-material da cidade é vista, [...] como socialmente construída" (p. 86). Dentro de qualquer um dos dois direcionamentos, a sustentabilidade urbana não pode prescindir do investimento em infraestruturas. 
A falta de investimentos em equipamentos urbanos acentua o déficit na oferta de serviços, aumentando a "segmentação socioterritorial entre populações atendidas e não-atendidas por tais serviços, incrementando os graus de conflito e incerteza no processo de reprodução das estruturas urbanas" (ACSELRAD, 1999, p. 86).

Do ponto de vista da eficiência, a visão promovida pelo Estado francês projeta na "cidade sustentável" o que Acselrad (1999) entende como os "[...] supostos atributos de atratividade de investimentos, no contexto da competição global" (p. 81). A visão da Região por sua vez, corresponde ao modelo estudado pelo autor, dentro do qual a cidade se coloca como "o espaço por excelência da invenção de direitos e inovações sociais" (p.88). Cada uma das propostas pode estar ligada seja à reprodução das estruturas existentes seja à inovação; as duas têm potencial de promover a sustentabilidade, cada uma dentro de uma lógica própria.

Entretanto, eficiência e igualdade precisam se equilibrar, devido à sua relação de estreita interdependência. Num território agem os fatores sociais, culturais, históricos, políticos e psicológicos, gerando situações de maior ou menor igualdade social. Quando a desigualdade - que, segundo Bordeau-Lepage (2013) "se traduz cada vez mais numa segregação espacial" (p. 416) - é muito elevada, ela gera instabilidade (por exemplo, manifestações violentas, depredação, problemas de segurança, etc.), o que prejudica a imagem da cidade global. Desta forma, o nível de igualdade social se reflete diretamente na capacidade que a cidade tem de atrair pessoas e investimentos.

Concluindo, então, é possível afirmar que o maior desafio para o GPE é estabelecer "limites de elasticidade das técnicas e das vontades políticas" que permitam a construção de uma "base técnico-material" para a metrópole, dentro de um cronograma que equilibre os diferentes aspetos da sustentabilidade urbana. Conforme já preconizado nas discussões durante a Grande Consulta, as ações deverão ser hierarquizadas ao longo do tempo, a partir da sua inserção nas escalas de importância (AIGP, 2012), de maneira a garantir um processo de produção e reprodução das estruturas urbanas que seja eficiente, mas também equânime. Só assim será possível compatibilizar a Cidade Global e a Cidade Justa. A oposição a uma transformação global e urbana regida pela "anônima lógica econômica" [...] (SMITH, 2006, p. 85) deverá, portanto, ter um papel crucial na configuração dos novos espaços. 


\section{Referências bibliográficas}

ANDRIOSOPOULOS, Kostas; SILVESTRE, Stephan. (2017). French energy policy: A gradual transition. Energy Policy. v. 106, pp. 376-381. <https://www.sciencedirect.com/science/article/pii/S0301421517302380>. Acesso em: 30 jan. 2018.

ARANTES, Otília F. (2000) Uma Estratégia Fatal: a cultura nas novas gestões urbanas. In: Arantes, O.; Vainer, C.;Maricato, E. (org). A Cidade do Pensamento Único: Desmanchando Consensos. Petrópolis: Vozes, pp. 11-73. Disponível em: <http://www.revistas.unifacs.br/index.php/rde/article/view/13/69> Acesso em: 30 set. 2017.

AUZENNET, P. (2012) Rapport de la mission sur le calendrier pluriannuel de réalisation et de financement du projet de Grand Paris Express, Relatório. 10 décembre 2012. Disponível em: <http://www.ladocumentationfrancaise.fr/var/storage/rapports-publics/124000665.pdf> Acesso em: 3 ago. 2017.

BECHERAND, P. E. Batir le patrimoine métropolitain du XXle siècle. Le Futur du Grand Paris se construit avec son temp. Dossier Les Gares du Grand Paris - Revue des Mines n.491, Mai juin 2017 p. 48-49

BELKIND, Lara. (2013). The Negotiated Urbanism of Grand Paris Express, Metropolitics, 12, não paginado June 2013. Disponível em: <http://www.metropolitiques.eu/The-Negotiated-Urbanism-of-Grand.html> Acesso em: 15 jan. 2018.

BERJMAN, Edgardo. (2011). Esquemas de metrô automático para a metropolização de Paris. Minha Cidade, São Paulo, ano 11, n. 126.01, Vitruvius, jan. 2011. Disponível em: <http://vitruvius.com.br/revistas/read/minhacidade/11.126/3723/pt>. Acesso em: 21 out. 2017.

BONTINCK, Jean-Gabriel (2017). Le Grand Paris Express, quel chantier ! Le Parisien, Paris, 27 décembre 2017. Disponível em: <http://www.leparisien.fr/info-paris-ile-de-france-oise/transports/le-grand-paris-express-quelchantier-27-12-2017-7473600.php> Acesso em: 30 dez. 2017.

BOURDEAU-LEPAGE, L. (2013) Introduction. Grand Paris: projet pour une métropole globale. Revue d'Économie Régionale \& Urbaine 2013/3 (août), p. 403-436. DOI 10.3917/reru.133.0403 Disponível em: https://www.cairn.info/revue-d-economie-regionale-et-urbaine-2013-3-page-403.htm. Acesso em: 06 jan. 2018.

CASTELLS, M. A era da informação: economia, sociedade e cultura. São Paulo: Paz e Terra, 1999. (A sociedade em rede, v.1)

CASTRO, M.B. O bonde na cidade: Transportes públicos desenvolvimento urbano. Sao Paulo AnnaBlume, 2007

CERQUEIRA, Eugênia Dória Viana. (2014). A evolução das formas de gentrificação: estratégias comerciais locais e o contexto parisiense. Cadernos Metrópole. São Paulo, v. 16, n. 32, pp. 417-436. Disponível em: <http://www.scielo.br/pdf/cm/v16n32/2236-9996-cm-16-32-0417.pdf>. Acesso em: 06 jan. 2018.

CHANG, Chun-Hao. The Central-Local Relationship and Constitutional Operations in France. Humanities and Social Sciences. vol. 4, n. 2, 2016, pp. 16-25. doi: 10.11648/j.hss.20160402.11

CHATHELAIN, Bernard. (2017) Le Futur du Grand Paris se construit avec son temp. Dossier Les Gares du Grand Paris. Revue des Mines. Paris, n.491, p. 44 45, Mai Juin 2017

DAMOUR, P. (2018). Le Grand Paris Express: Combien des stations au final? Challenges. Paris. pp. 03-02. Disponível em: <https://www.challenges.fr/entreprise/transports/le-grand-paris-express>

ENRIGHT, Theresa. (2013). Mass transportation in the neoliberal city: The mobilizing myths of the Grand Paris Express. Environment and Planning. v.45, n.4. pp. 797-813. Disponível em: <http://journals.sagepub.com/doi/abs/10.1068/a459>. Acesso em: 07 fev. 2018.

FAINSTEIN, S. (2010) The just city. Cornell University Press, Ithaca.

FAURE, A. (2018) Finances du Grand Paris: la faillite du politique The conversation February 4, 2018. Disponível em: <https://theconversation.com/finances-du-grand-paris-la-faillite-du-politique-90267> Acesso em: 28 fev. 2018.

FRANÇA (2010). Loi $n^{\circ} 2010-597$ du 3 juin 2010. Relative au Grand Paris. Disponível em: <https://www.legifrance.gouv.fr/eli/loi/2010/6/3/2010-597/jo/texte>. Acesso em 16 jan. 2018. 
GAIGNÉ, Carl; RIOU Stéphane; THISSE, Jacques-François. (2012) Are compact cities environmentally friendly? Journal of Urban Economics, n.72. pp. 123-136.

GALLEZ, Caroline. (2014) Contrats de développement territorial in the Grand Paris project: towards negotiated networked development? Town planning review.v.85. n2 pp.273-286. Disponível em: <http://online.liverpooluniversitypress.co.uk/doi/abs/10.3828/tpr.2014.17> Acesso em: 15 nov. 2018.

GONGUET, J.P. (2017) Quelle sera l'efficacité du Grand Paris Express? Le monde, Paris 15.12.2017 <http://www.lemonde.fr/societe/article/2017/12/15/quelle-sera-l-efficacite-du-grand-parisexpress 5230320 3224.html\#yeMtILfk6rGjDYUU.99> Acesso em: 15 nov. 2017.

GUSDORF, F; HALLEGATTE, S. (2007) Compact or spread-out cities: Urban planning, taxation, and the vulnerability to transportation shocks. Energy Policy. n.35. pp. 4826-4838

HARVEY, David. (1996). Do Gerenciamento ao Empresariamento: a transformação da administração urbana no capitalismo tardio. São Paulo: Espaço \& Debates, v. 16, n. 39, pp. 48-64.

HARVEY, David. (2001). Spaces of Capital: Towards a Critical Geography. New York: Routledge.

JACQUE, P. (2017). Grand Paris: le chantier du siècle est enfin lancé. Le monde Economie, Paris. 27.05.2017. Disponível em: <http://www.lemonde.fr/economie/article/2017/05/27/grand-paris-le-chantier-du-siecle-est-enfinlance 5134543 3234.html\#xFC4qzCSOqGZ8QEV.99> Acesso em: 15 nov. 2017

JACQUES, Paola Berenstein. (2005). Errâncias Urbanas: A arte de andar pela cidade. ArqTexto, Porto Alegre. v. 7, $\quad$ n. 1 1, pp. 16-25. Disponível em: <https://www.ufrgs.br/propar/publicacoes/ARQtextos/PDFs_revista_7/7_Paola\%20Berenstein\%20Jacques.pdf >. Acesso em: 08 jan. 2018.

JLL. (2016?). Site da empresa de consultoria estratégica em imobiliária dedicado ao projeto GPE. Qu'est-ce que le projet du Grand Paris? Disponível em: <http://www.grand-paris.jll.fr/fr/projet-grand-paris/presentationgenerale/>. Acesso em: 16 jan. 2018.

MADUREIRA, Helena (2005). Paisagem urbana e desenvolvimento sustentável: apontamentos sobre uma estreita relação entre geografia, desenvolvimento sustentável e forma urbana. X Colóquio Ibérico de Geografia, X. Anais... não paginado. Évora. Disponível em <https://repositorioaberto.up.pt/bitstream/10216/25612/2/72269.pdf> Acesso em: 15 nov. 2017

MAYER, Thierry; TREVIEN B, Corentin. (2016). The impact of urban public transportation evidence from the Paris region. Journal of Urban Economics. n. 102, pp 1-21.

POUTHIER, A. MOUTARDE, N. (2018). Le Grand Paris Express sera bouclé à I'horizon; 2030. Le Moniteur. Paris. Data. Disponível em: <https://www.lemoniteur.fr/article/le-grand-paris-express-sera-boucle-a-I-horizon2030.1952424 $\geq$ Acesso em: 15 mar. 2018

RENAUD F; EL KAIDI, K. (2017) La Ligne 14: le grand pari du défi et de l'innovation. Dossier Les Gares du Grand Paris. Revue des Mines. Paris, n.491, p. 52 53, Mai juin 2017

ROGERS, Richard; GUMUCHDJIAN, Philip. (1997) Cidades para um pequeno planeta. Barcelona, Editorial Gustavo Gili.

SALAT, Serge; BOURDIC, Loeiz.(2016) L'economie spatiale du Grand Paris: Connectivité et création de valeur. Synthèse du rapport. Institut des Morphologies Urbaines et des Systèmes Complexes; Caisse de depots, Institut CDC pour la recherche. Janvier 2016. Disponível em: <http://www.urbanmorphologyinstitute.org/wpcontent/uploads/2016/01/Executive-summary-rapport-Grand-Paris.pdf>. Acesso em: 06 fev. 2018.

SANTOS, Milton (1988). Metamorfoses do Espaço Habitado. São Paulo: Hucitec.

SASSEN, S. (2005) The Global City: introducing a Concept. The Brown Journal of World Affairs. v.11, n. 2, pp. 27-43 Winter/Spring 2005. Disponível em: <http://www.saskiasassen.com/pdfs/publications/the-global-citybrown.pdf> Acesso em: 15 nov. 2017

SCHWANEN, Tim. (2016). Geographies of transport I: Reinventing a field?. Progress in Human Geography. v. 40, n. 1, pp. 126-137. Disponível em: <http://journals.sagepub.com/doi/10.1177/0309132514565725>. Acesso em: 29 jan. 2018. 
SCHWARZBACH. Yves. (2016)_Grand Paris Express, Saison 9, Episode 1: La ligne rouge. Centralités du Grand Paris. Paris, n.7 , pp 62-70. Mai 2016. disponivel em <http://centralites.com/centralites7.htm> Acesso em: 20 nov. 2017

SMITH, Neil. (2006). A gentrificação generalizada. In: BIDOU-ZACHARIASEN, Catherine. De volta à cidade: dos processos de gentrificação às políticas de "revitalização" dos centros urbanos. São Paulo: Annablume, p.59-87.

THE SKELETON CREW: Crossrail. The Economist, 22 Apr. 2017, p. 68(US). Academic OneFile, Disponivel em: http://link.galegroup.com/apps/doc/A490274325/AONE?u=capes\&sid=AONE\&xid=7d603677. Acesso em: 6 Nov. 2018.

THORIN, B. (2017). L’accessibilité des gares e t de poles gares; Fluidités, simplicités e lisibilité des espaces. Dossier Les Gares du Grand Paris. Revue des Mines, Paris, n.491, 2017 p. 5455 Mai juin 2017.

YVIN, Philippe, interview a Dossier Les Gares du Grand Paris - Revue des Mines, Paris, n.491, Mai juin 2017 p. 39-41

ZORZO, Francisco Antônio. 2009. A Emergência do Capitalismo Ferroviário na Europa na Segunda Metade do Século XIX: a Implantação da Ferrovia na França, Itália e Espanha. SIMPÓSIO NACIONAL DE HISTÓRIA ANPUH, 25; Fortaleza. 